\title{
Executive and Non-Executive Cognitive Abilities in Teenagers: Differences as a Function of Intelligence
}

\author{
Silvia Godoy ${ }^{1}$, Natália Martins Dias ${ }^{2}$, Alessandra Gotuzo Seabra ${ }^{3}$ \\ ${ }^{1}$ Faculdades Integradas Einstein de Limeira, Limeira, Brazil \\ ${ }^{2}$ The Post-Graduation Program in Educational Psychology, Centro Universitário FIEO, Osasco, Brazil \\ ${ }^{3}$ The Master's and Doctoral Program in Developmental Disorders, Universidade Presbiteriana Mackenzie, \\ São Paulo, Brazil \\ Email: ${ }^{*}$ silviagodoy04@yahoo.com.br
}

Received 5 September 2014; revised 1 October 2014; accepted 23 October 2014

Copyright (C) 2014 by authors and Scientific Research Publishing Inc.

This work is licensed under the Creative Commons Attribution International License (CC BY). http://creativecommons.org/licenses/by/4.0/

(c) (i) Open Access

\begin{abstract}
Intelligence and cognitive abilities, including executive functions (EF), have been addressed by psychometrics and cognitive psychology, respectively. Studies have found similarities and overlap among constructs, especially between EF and fluid intelligence (Gf). This study's aim was to investigate in teenagers: 1 ) the relationships among $G f$, crystallized intelligence $(G c)$, cognitive, and executive abilities; and 2) the differences among groups with average, superior and very superior intelligence in regard to cognitive and executive functions. A total of 120 adolescents aged between 15 and 16 years old were assessed via IQ tests (the WISC III and Raven's), EF (computer version of the Stroop Test, FAS Verbal Fluency Test, Trail Making Test-part B), and cognitive abilities (Peabody Picture Vocabulary Test [PPVT], Repetition of words and pseudo words Test, the Rey Complex Figure [REY CF]). Low to moderate correlations were found among measures of intelligence and cognitive and executive functions. Even though interrelated, the measures seem to capture somewhat distinct aspects. Subsequently, the participants were divided into three groups according to their performance on Raven's Test: Group with very superior intelligence (VSI), Group with superior intelligence (SI), and Group with average intelligence (AI). The ANOVA revealed the groups' significant effect (VSI, SI, AI), that is, the VSI and SI groups tended to perform better on the WISC subtests, in the cognitive measures of the PPVT, Rey CF, and in executive measure (FAS). A tendency of increasingly better performance in the various abilities according to groups was observed, but the hypothesis of greater specific association between $\mathrm{G} f$ and $\mathrm{EF}$ was not confirmed. The results show better general performance according to the level of intelligence.
\end{abstract}

${ }^{*}$ Corresponding author.

How to cite this paper: Godoy, S., Dias, N. M., \& Seabra, A. G. (2014). Executive and Non-Executive Cognitive Abilities in Teenagers: Differences as a Function of Intelligence. Psychology, 5, 2018-2032.

http://dx.doi.org/10.4236/psych.2014.518205 


\section{Keywords}

\section{Psychometrics, Assessment, Cognition}

\section{Introduction}

Psychometrics has traditionally studied intelligence, while cognitive abilities, including the so-called executive functions (EF), have been addressed by cognitive psychology and neuropsychology. This study focuses on the relationships among these constructs, concepts originally derived from different theoretical fields.

Intelligence can be understood as an ability to learn from experience and adapt to the environment (McGrew, 2009). Historically, various theories have been proposed in an attempt to delimit this concept, including Spearman's proposition (Mcgrew \& Flanagan, 1998), which concerns a general factor known as $g$ that would permeate all cognitive tasks and accomplishments. One of the most influential theories, even today, refers to the idea of fluid (Gf) and crystalized (Gc) intelligence proposed by Carroll (1993) and Cattell (1987). Gf is associated with non-verbal components, having little dependence on prior knowledge or on the influence of cultural aspects (Horn, 1991; McGrew, 1997) and has been strongly associated with g (Gustafsson, 1988; Härnqvist, Gustafsson, Muthén, \& Nelson, 1994). Gc, in turn, refers to prior knowledge and represents abilities required in the solution of most everyday problems and is developed from cultural and educational experiences (Cattell, 1998; Horn, 1991; Horn \& Noll, 1997).

The development of the dichotomous Gf-Gc model resulted in the Cattell-Horn-Carroll (CHC) theory of cognitive abilities, described as an empirically assessed integration of conceptions developed by Cattell, Horn and Carroll (Schelini, 2006). The CHC model understands intelligence as consisting of a three-level hierarchy. The highest level refers to Spearman's g factor, suggesting that a common ability underlies all the cognitive abilities. There are 15 broad factors in the second level, and the lower level aggregates approximately 80 specific factors that correspond to abilities more directly assessed by IQ tests (Mcgrew, 2009).

In turn, according to views based in neuropsychology, behavior is based on three major functional systems that, in addition to emotional aspects related to personality and emotion variables, include cognitive and executive functions (Lezak, Howieson, \& Loring, 2004). Cognitive functions involve behavioral aspects related to information processing. Executive functions reflect an individual's ability to engage in independent and selfregulated behavior. Considering that $\mathrm{EF}$ are also, to a certain extent, cognitive functions, we use in this paper the terminology "non-executive cognitive functions" to refer to information-processing abilities in order to differentiate between both constructs.

Cognitive functions encompass diverse abilities involved in information recording (input), its processing, maintenance and response (output). Among them, we address in this study linguist abilities, such as vocabulary and phonological short-term memory, and visual-spatial abilities, such as perception and visual short-term memory. Vocabulary corresponds to words with which the individual is familiar and is able to reproduce and/or understand, relating them to the language's semantic aspects (Sternberg, 2008). Phonological short-term memory refers to one's ability to retain and recover phonological information for short periods of time (Vance, 2004). Visual-spatial ability refers to the processing of visual mental representations and may be further divided into visual abilities, which include color and movement processing, and spatial abilities, which include visual localization, spatial attention, spatial knowledge and reasoning (Sternberg, 2008). According to the author, among visual abilities, visual perception is a set of processes that enables recognizing, organizing, and interpreting information based on visual sensory stimulation, while visual memory refers to one's ability to retain and recover visual representation in the absence of stimuli.

EF, in turn, refer to one's ability to engage in objective-based behavior (Sullivan, Riccio, \& Castillo, 2009). Three abilities are considered major EF: inhibition, which enables one to control inappropriate behavior and attention to distractors (selective attention); working memory that is responsible for maintaining and mentally handling information; and cognitive flexibility, which enables changing perspectives and adapting to different contexts (Diamond, 2013; Miyake et al., 2000). These main abilities are involved in and can promote other complex EF such as planning, decision-making, and even fluency (Dias \& Seabra, 2014; Malloy-Diniz et al., 2008; Miyake et al., 2000). From this perspective, EF cover "how" an individual does something, while cognitive 
functions cover "what and how much" an individual is capable of.

Some overlap is identified among these concepts. For instance, the proposition of Diamond (2013) regarding EF integrates the concept of Gf. The author considers the interaction among major EF, inhibition, working memory and flexibility to be the base for more complex executive abilities, such as reasoning and problem-solving, which the author considers to be synonymous with Gf. In addition, Arffa (2007) considers EF to overlap with the psychological concept of intelligent behavior. The multidimensionality of these constructs complicates the relationship and reveals overlaps, which can, in turn, change over development. This situation has led some researchers to investigate in more detail the relationships among intelligence, cognitive and executive functions in specific age ranges. For instance, Demetriou et al. (2014) analyzed speed and working memory as predictors of $\mathrm{G} f$, and found that speed-G $f$ and Working Memory-G $f$ relations change in different age ranges.

The relationship between IQ tests and EF tests in general are usually not strong. A more careful analysis of this correlation in children, however, reveals that associations between EF tests and IQ tests with greater emphasis on Gc tend to be weak, while the relationship between EF tests and Gf tests tends to be stronger (Arffa, 2007). Additionally, even among EF-related abilities, some are more strongly associated with intelligence measures than others. For instance, in adults, working memory, and more specifically the central executive component, appears more strongly related both to $\mathrm{Gc}$, and especially to $\mathrm{G} f$ intelligence, while the relationship with other executive abilities is less consistent (Abreu, Siquara, Leahy, Nikaedo, \& Engel de Abreu, 2014; Friedman et al., 2006). Also, Demetriou et al. (2014) demonstrated that working memory is a strong predictor of Gf in some periods of development, as 13 - 16 age range. For this reason, given the amount of evidence involving working memory (see Abreu et al., 2014 for a review), this study focused on other executive abilities in teenagers: two major abilities (inhibition and flexibility) and one complex ability (verbal fluency).

Another line of investigation has included studies addressing individuals with brain injuries. Evidence shows that both EF as Gf or Spearman's $g$ factor share some neural substrates and are associated with the prefrontal cortex (Barbey et al., 2012; Roca et al., 2010). Studies show that prefrontal alterations are associated with Gf loss, however, they do not seem to change Gc (Roca et al., 2010). This relationship between prefrontal areas, known as the EF substrate, and Gf raises questions in regard to the relationship between these two constructs. In fact, studies have shown the contribution of Gf, together with working memory and inhibition, to solving EF traditional tests, such as the Tower of London, which assess planning (Zook, Dávalos, Delosh, \& Davis, 2004). Neuroimaging studies agree that the prefrontal cortex is a neurological subtract common to both EF and Gf (Abreu et al., 2014).

In addition to $\mathrm{G} f-\mathrm{G} c$, EF are also related to the $\mathrm{CHC}$ model's cognitive abilities. Based on the performances of children and adolescents in an EF battery (Kaplan Executive Function System-DKEFS) and Woodcock-Johnson III, which assesses cognitive abilities, the authors found positive and significant correlations between the participants' performances on both instruments concluding that there are similarities among the constructs assessed in IQ tests and neuropsychological batteries (Floyd, Bergeron, Hamilton, \& Parra, 2010).

Even though WISC-III and WAIS-III were not based on the Gc-Gf or CHC and are considered to present a heavy load of Gc (Primi, 2003), studies have shown some relationships between total IQ or score in subtests, and EF (Ardila, Pineda, \& Rosselli, 2000; Riccio, Hall, Morgan, \& Hynd, 1994; van Aken et al., 2014). Arffa (2007), for instance, assessed three groups of children and young individuals divided according to the total IQ obtained on the WISC-III into groups with average intellectual ability (IQ between 90 and 114), above average (IQ from 115 to 129), and gifted (IQ above 130). The author verified that the performance obtained on EF tests (except flexibility) is significantly correlated with total IQ. The group of gifted children presented higher performance on EF tests when compared to the other two groups, but this superior performance was not observed on non-executive tests assessing other cognitive abilities.

In this context, this study has a twofold objective: 1) to investigate the relationships among Gf, Gc, executive and non-executive abilities; and 2) to investigate the differences among groups with average intelligence, superior intelligence, and very superior intelligence, considering cognitive functions (vocabulary, short-term memory, visual processing), including the WISC-III tests, and executive abilities (selective attention/inhibitory control, verbal fluency and cognitive flexibility). Arffa (2007) divided groups according to a measure with a high load of Gc. In this study, the groups were divided according to their performance in a test with a heavier load of Gf. The hypothesis is that there is a differential pattern of relationships among the variables, with more and stronger relationships established between the executive and Gf measures. Another assumption is that the groups with higher percentiles of intelligence will perform better on all the tasks, but more specifically in EF measures. 


\section{Method}

\subsection{Participants}

The initial sample was composed of 139 adolescents aged from 15 to 16 years old, attending high school (64\% female) in both public and private schools in the state of São Paulo. Intellectual disability, identified through Raven's Progressive Matrices Test-General Scale, was an exclusion criterion. Hence, those classified with a percentile below 25 were excluded from the sample. There were no participants with any known, uncorrected severe sensory or motor disability. The final sample was composed of 120 adolescents, aged from 15 to 16 years old (68.3\% females). Of these, $37.5 \%$ were attending the $1^{\text {st }}$ year and $62.5 \%$ were attending the $2^{\text {nd }}$ year of high school; $88.3 \%$ of the students were from private schools. The 120 participants were divided into three groups according to their performance on Raven's Progressive Matrices Test-General Scale: group with Very Superior Intelligence (VSI), with a percentile equal or above 90; group with Superior Intelligence (SI) with percentile between 75 and 89; and group with Average Intelligence (AI) with percentiles from 25 to 74). The characterization of the groups is presented in Table 1. This grouping (at the expense of other possible groupings) was intended to keep a reasonable number of participants per group.

\subsection{Instruments}

\subsubsection{Raven's Progressive Matrices Test-General Scale}

Raven’s Progressive Matrices Test—General Scale (Angelini, Alves, Custódio, Duarte, \& Duarte, 1999) assesses one's general reasoning ability, suitable for assessing individuals 12 years old or older. It is composed of a book with 60 items divided into five series (A, B, C, D and E). Each series contains 12 problems ordered by level of difficulty. A figure in which one entry is missing is presented in each problem. A set of answer choices is presented for the missing entry. The participant must choose the option that completes the figure. Raven's test has a heavy load of g factor (Primi, 2003). In this study, scores obtained on Raven's test was used to exclude participants with intellectual disability and to assign the participants into groups (VSI, SI, AI). The instrument was applied collectively and the application lasted approximately 20 minutes.

\subsubsection{Wechsler Intelligence Scale for Children (WISC-III)}

The WISC-III (Figueiredo, 2002) assesses the intellectual ability of children aged from 6 to 16 years old. It is composed of subtests organized into two groups, Verbal and Performance, each assessing different aspects of intelligence. The verbal scale provides information on language processing, reasoning, attention, verbal learning and memory, while the performance scale enables the assessment of visual processing, planning ability, non-verbal learning and ability to manipulate visual stimulation. In addition to these two scales, the instrument yields a total IQ and the estimate of four factor scores: Factor 1-Verbal Comprehension; Factor II-Perceptual Organization; Factor III-Resistance to Distraction; and Factor IV—Processing Speed.

Eight subtests were used in this study, which allowed the Factor Score Verbal Comprehension (Factor 1) and Perceptual Organization (Factor II) to be estimated. In regard to the scale Verbal Comprehension, the "information" subtest measures the level of knowledge acquired from formal education and family upbringing, enabling the verification of temporal organization. The "similarities" subtest examines one's ability to establish logical relationships and verbal concepts or categories. "Vocabulary" assesses one's linguistic competence, lexical knowledge, and, mainly, ease at preparing speech. Finally, the "Comprehension” subtest refers to the individual's ability to express experiences and knowledge concerning social relationship rules. In regard to the Perceptual Organization scale, the "Complete Figures" subtest involves visual memory and lexical access because the

Table 1. Description of participants divided by groups: number of subjects, percentage by group, and percentile in raven.

\begin{tabular}{cccc} 
Groups & $\mathrm{N}$ & $\%$ & Percentile \\
\hline Very superior intelligence & 18 & 15.0 & 92.89 \\
Superior intelligence & 18 & 15.0 & 81.94 \\
Average intelligence & 84 & 70.0 & 45.36 \\
Total & 120 & 100 & 60 \\
\hline
\end{tabular}


participant is asked to indicate the part missing in a figure. The "Figure Arrangement" subtest requires perceptive analysis, as well as ability to integrate a set of available information. The "Cubes" subtest examines organization and visual-spatial/non-verbal processing, i.e. the ability to mentally decompose elements of a model to be replicated. It is considered a non-verbal problem-solving measure. Finally, the “Assembly Objects” measures one's ability to organize a whole from separated elements, assessing perceptive integration and problem-solving strategy. According to Furgueson, Greenstein, Mcguffin and Soffer (1999), the summarized versions of the WISC-III are a reasonable alternative to assess children's cognitive abilities. The instrument was individually applied and took one hour, on average.

\subsubsection{Computer Version of the Stroop Test (Stroop-Comp)}

The Stroop-Comp (Seabra, Dias, \& Macedo, in press) assesses selective attention and inhibitory control. The test is composed of three parts, each with 24 stimuli. The first part presents, for an undetermined time, the names of four colors (yellow, blue, green, and red) written in black capital letters. These words must be read as fast as possible in order to assess reading abilities. The instrument's second part presents 24 colored circles (yellow, blue, green, and red) exposed on the screen for 40 thousandth of a second. The participant's task is to name the color of each circle. This part of the test serves as the baseline to analyze correct answers and reaction time on the third part of the instrument. In this part, the circles are replaced by written words that correspond to the four colors but which are printed in colors different from their meaning (e.g. the word green is written in blue and so on) and the individual is asked to name the color with which the word is written. This stage demands new processing (inhibit the tendency to read and select the relevant stimulus, in this case, color). The effect of interference is obtained by subtracting the score obtained on the second part of the instrument from the score obtained on the third part of the Stroop-Comp, both in terms of score and reaction time (RT). The instrument was individually applied for 20 minutes, on average. In this study we used the score and RT obtained for the third part of the instrument and for interference.

\subsection{FAS Semantic Verbal Fluency Test (FAS)}

The FAS assesses verbal fluency (Strauss, Sherman, \& Spreen, 2006). A computer version was used, in which six screens were presented to the participants. The first screen prompts participants to "Say as many words starting with the letter F as you can. You have one minute.” The screen remains empty and the participant has one minute to answer. The examiner controls time and the software records the participant's responses. The same procedure is then repeated with the letters A and S. The instrument was individually applied and took approximately 5 minutes. For this study, we used the total number of words correctly evoked.

\subsubsection{Trail Making Test-Part B (TMT)}

TMT (Montiel \& Seabra, 2012) assesses cognitive flexibility. It consists of the presentation of 24 items represented by 12 letters (from A to $\mathrm{M}$ ) and 12 numbers (from 1 to 12), randomly dispersed on a white sheet of paper. The participant's task is to link letters and numbers interchangeably in ascending order for the numbers and alphabetically for the letters. One minute is allowed for the task. The instrument was collectively applied. Scores obtained for the sequences and connections were used.

\subsubsection{Peabody Picture Vocabulary Test (PPVT)}

The PPVT (Dunn \& Dunn, 1981) assesses receptive vocabulary in a wide variety of fields, including people, actions, qualities, body parts, time, nature, places, objects, animals, mathematical terms, tools and instruments. The test comprises 125 items and each item is composed of four drawings. The task consists of selecting, among the alternatives, the figure that best represents the word spoken by the examiner. The test was collectively applied and lasted 30 minutes, on average. The total score obtained on the instrument was used.

\subsubsection{Words and Pseudo Words Repetition Test (WPwRT)}

The WPwRT (Seabra, 2012) assesses short-term phonological memory. The examiner pronounces sequences from two to six words, with a one-second interval between words. The participant's task is to repeat the words in the same sequence. There are two sequences for each word grouping; that is, two sequences with two words, two sequences with three words, and so on. Afterwards, sequences with pseudo words were presented, that is, 
made-up words that do not have any meaning. There are also two sequences for each group of words, ranging from two to six pseudo words per sequence. The test was individually applied and took 10 minutes, on average. The total score obtained on the instrument was used.

\subsubsection{Rey Complex Figures Test (Rey-CF)}

Rey-CF (Rey, 1999) assesses visual perception and immediate recall, respectively, by the participant copying the figure and then reproducing the figure from memory. The test enables verifying how the individual perceives perceptual data and what is spontaneously stored in memory. It consists of a complex geometrical and abstract figure. First, the individual is asked to copy the stimulus figure with the highest level of detail possible. Three minutes later the participant is asked to draw the same figure, however, this time without the stimulus: the participant must rely on memory to reproduce the figure. Scoring is based on accuracy and detail, both in regard to the copy and to the reproduction from memory. Time taken to perform each part of the test is also recorded. The test was collective applied and lasted approximately 20 minutes. The scores and time used to perform each part of the test, for copying and immediate recall, were used.

\subsection{Procedure}

The project was approved by the Institutional Ethics Board and the legal guardians of the study participants signed free and informed consent forms. Data were collected during the $2^{\text {nd }}$ semester of the school year on the schools' premises during regular school hours. The participants were removed from their classrooms only after gaining their consent and that of their teachers. The instruments were applied in a collective session with 15 students, at most, in a classroom for approximately 90 minutes (Raven's Test, Rey-FC, TMT and PPVT). There were also two individual sessions of approximately 30 minutes (Stroop-Comp, FAS and WPwRT), and another session of approximately 60 minutes (WISC-III subtests).

\subsection{Data Analysis}

Pearson's correlation was used to verify the relationship between the percentiles obtained on Raven's test and the WISC-III's IQ of verbal comprehension and IQ of perceptual organization, as well as the correlation between measures of intelligence and the other instruments. Variance analysis (ANOVA) was performed in regard to the group's effect (VSI versus SI versus AI) on the measures of various instruments. A $p \leq 0.05$ was used in all the comparisons. Tukey's pairwise comparison analysis was also used.

\section{Results}

We first verified the relationship between fluid intelligence, measured by Raven's Test, the IQ of verbal comprehension and IQ of perceptual organization measured by the WISC-III. A positive and significant relationship was found between the Raven's percentiles and both measures of verbal comprehension IQ $(r=0.61, p<0.001)$ and perceptual organization IQ $(r=0.45, p<0.001)$. Table 2 presents the correlations between measures of intelligence and performance on the tests of executive and non-executive abilities. All the measures of intelligence were significantly correlated with performance on the Trail and FAS verbal fluency tests, though correlations were weak. Only the measure of Verbal Comprehension was significantly correlated with the Stroop measures, though with a low magnitude. In regard to the non-executive measures, correct answers obtained in the Rey-CF immediate recall were significantly correlated with all the intelligence measures, but also with a low magnitude. Correct answers in the copy exercise were significantly correlated with Raven's measure. Moderate correlations were found only between performance on the PPVT and intelligence measures.

We opted in this study to assign participants to groups according to scores obtained on the Gf measure and three groups were formed, as previously discussed in the Participants session. The ANOVA showed that the groups had a significant effect on the various measures. A tendency for groups with superior and very superior intelligence to perform better was observed in all the cases. Significant effects were found in the scores obtained in Vocabulary, Information, Similarities, Comprehension, Figure Arrangement, Cubes, Assembly Objects, and Verbal Comprehension IQ and Perceptual Organization IQ. Only in regard to Complete Figures were no differences found in the performance of groups. Significant effect was also observed in regard to the remaining measures in vocabulary (PPVT) and measures of visual perception and memory (copy accuracy and reproduction 
Table 2. Matrix of correlations between measures of intelligence and performance in executive and non-executive tests for the overall sample.

\begin{tabular}{|c|c|c|c|c|}
\hline & & Raven Percentile & Verbal Comprehension IQ & Perceptual Organization IQ \\
\hline \multirow{2}{*}{ Stroop-part 3 score } & $r$ & 0.17 & 0.28 & 0.16 \\
\hline & $p$ & 0.060 & 0.002 & 0.082 \\
\hline \multirow{2}{*}{ Stroop-part 3 RT } & $r$ & -0.17 & -0.19 & -0.08 \\
\hline & $p$ & 0.070 & 0.037 & 0.402 \\
\hline \multirow{2}{*}{ Stroop interference score } & $r$ & 0.18 & 0.26 & 0.16 \\
\hline & $p$ & 0.051 & 0.004 & 0.089 \\
\hline \multirow{2}{*}{ Stroop interference RT } & $r$ & -0.09 & -0.19 & -0.10 \\
\hline & $p$ & 0.333 & 0.036 & 0.285 \\
\hline \multirow{2}{*}{ Verbal Fluency FAS } & $r$ & 0.31 & 0.38 & 0.28 \\
\hline & $p$ & 0.001 & 0.001 & 0.002 \\
\hline \multirow{2}{*}{ TMT—sequence B } & $r$ & 0.28 & 0.28 & 0.32 \\
\hline & $p$ & 0.002 & 0.002 & 0.001 \\
\hline \multirow{2}{*}{ TMT_connection B } & $r$ & 0.30 & 0.33 & 0.40 \\
\hline & $p$ & 0.001 & 0.001 & 0.001 \\
\hline \multirow{2}{*}{ PPVT total } & $r$ & 0.43 & 0.60 & 0.51 \\
\hline & $p$ & 0.001 & 0.001 & 0.001 \\
\hline \multirow{2}{*}{ WPwRT total } & $r$ & 0.15 & 0.09 & 0.06 \\
\hline & $p$ & 0.101 & 0.320 & 0.551 \\
\hline \multirow{2}{*}{ Rey-CF_copy_score } & $r$ & 0.24 & 0.14 & 0.11 \\
\hline & $p$ & 0.008 & 0.127 & 0.231 \\
\hline \multirow{2}{*}{ Rey-CF_copy_time } & $r$ & 0.10 & -0.02 & 0.01 \\
\hline & $p$ & 0.333 & 0.869 & 0.922 \\
\hline \multirow{2}{*}{ Rey-CF_memory_score } & $r$ & 0.31 & 0.31 & 0.46 \\
\hline & $p$ & 0.001 & 0.001 & 0.001 \\
\hline \multirow{2}{*}{ Rey-CF_-memory_time } & $r$ & 0.01 & -0.09 & 0.02 \\
\hline & $p$ & 0.907 & 0.337 & 0.863 \\
\hline
\end{tabular}

Note: RT-Reaction time.

from memory on the Rey-FC). No difference was found in the measure of short-term phonological memory (WPWRT). In regard to the EF tests, the effect of the groups was evidenced in the measure of verbal fluency, though there were no effects on the measures of flexibility (TMT) or attention/inhibitory control (Stroop-Comp). These results are summarized in Table 3. Descriptive statistics (means and SD) for the whole sample and full correlation matrix are provided in Appendix.

\section{Discussion}

The analysis of correlations among performances on the intelligence tests showed that, even though they are interrelated, the measures capture relatively distinct aspects. The relationships observed in the intelligence measures and executive and non-executive tests tended to be weak, except for the vocabulary measure, which 
Table 3. Descriptive and inferential statistics of the effect of group on the measures.

\begin{tabular}{|c|c|c|c|c|c|c|}
\hline Variable & $\begin{array}{c}\text { VSI } \\
\text { score (SD) }\end{array}$ & $\begin{array}{c}\text { SI } \\
\text { score (SD) }\end{array}$ & $\begin{array}{c}\text { AI } \\
\text { score (SD) }\end{array}$ & $\begin{array}{c}F \\
(2.119)\end{array}$ & $p$ & $\begin{array}{c}\text { Posthoc } \\
\text { comparison-Tukey }\end{array}$ \\
\hline Information & $\begin{array}{l}16.67 \\
(1.45)\end{array}$ & $\begin{array}{l}15.78 \\
(1.55)\end{array}$ & $\begin{array}{l}14.20 \\
(2.65)\end{array}$ & 9.70 & 0.001 & $\mathrm{VSI}>\mathrm{AI}$ \\
\hline Similarities & $\begin{array}{l}13.94 \\
(3.57)\end{array}$ & $\begin{array}{l}11.94 \\
(2.79)\end{array}$ & $\begin{array}{l}10.92 \\
(2.31)\end{array}$ & 10.25 & 0.001 & VSI. SI > AI \\
\hline Vocabulary & $\begin{array}{l}14.72 \\
(2.10)\end{array}$ & $\begin{array}{l}15.50 \\
(1.88)\end{array}$ & $\begin{array}{l}13.67 \\
(2.17)\end{array}$ & 6.44 & 0.002 & $\mathrm{SI}>\mathrm{AI}$ \\
\hline Comprehension & $\begin{array}{l}13.06 \\
(3.03)\end{array}$ & $\begin{array}{l}11.67 \\
(1.49)\end{array}$ & $\begin{array}{l}10.64 \\
(1.51)\end{array}$ & 13.89 & 0.001 & VSI $>$ SI.AI \\
\hline Complete Figures & $\begin{array}{l}14.67 \\
(2.19)\end{array}$ & $\begin{array}{l}14.39 \\
(1.85)\end{array}$ & $\begin{array}{l}13.83 \\
(1.96)\end{array}$ & 1.62 & 0.201 & - \\
\hline Figure Arrangement & $\begin{array}{l}14.39 \\
(2.68)\end{array}$ & $\begin{array}{l}14.83 \\
(1.54)\end{array}$ & $\begin{array}{l}12.77 \\
(2.45)\end{array}$ & 7.68 & 0.001 & $\mathrm{SI}>\mathrm{AI}$ \\
\hline Cubes & $\begin{array}{l}14.06 \\
(1.05)\end{array}$ & $\begin{array}{l}14.33 \\
(1.53)\end{array}$ & $\begin{array}{l}12.31 \\
(2.32)\end{array}$ & 10.41 & 0.001 & VSI. SI > AI \\
\hline Assembly Objects & $\begin{array}{l}13.06 \\
(2.10)\end{array}$ & $\begin{array}{l}13.22 \\
(0.87)\end{array}$ & $\begin{array}{l}12.00 \\
(1.92)\end{array}$ & 4.89 & 0.009 & - \\
\hline Verbal Comprehension IQ & $\begin{array}{l}127.17 \\
(8.67)\end{array}$ & $\begin{array}{l}121.83 \\
(5.98)\end{array}$ & $\begin{array}{l}113.55 \\
(7.22)\end{array}$ & 30.83 & 0.001 & $\mathrm{VSI}>\mathrm{SI}>\mathrm{AI}$ \\
\hline Perceptual Organization IQ & $\begin{array}{l}125.89 \\
(9.56)\end{array}$ & $\begin{array}{l}126.44 \\
(6.90)\end{array}$ & $\begin{array}{l}117.02 \\
(9.85)\end{array}$ & 11.83 & 0.001 & VSI. SI > AI \\
\hline Stroop-part 3 score & $\begin{array}{l}0.969 \\
(0.06)\end{array}$ & $\begin{array}{l}0.969 \\
(0.04)\end{array}$ & $\begin{array}{l}0.955 \\
(0.05)\end{array}$ & 0.83 & 0.435 & - \\
\hline Stroop-part $3 \mathrm{RT}$ & $\begin{array}{l}0.741 \\
(0.49)\end{array}$ & $\begin{array}{l}0.768 \\
(0.43)\end{array}$ & $\begin{array}{l}0.790 \\
(0.15)\end{array}$ & 0.23 & 0.789 & - \\
\hline Stroop interference score & $\begin{array}{c}-0.018 \\
(0.05)\end{array}$ & $\begin{array}{c}-0.018 \\
(0.03)\end{array}$ & $\begin{array}{c}-0.033 \\
(0.05)\end{array}$ & 0.93 & 0.395 & - \\
\hline Stroop interference RT & $\begin{array}{l}0.305 \\
(0.49)\end{array}$ & $\begin{array}{l}0.350 \\
(0.45)\end{array}$ & $\begin{array}{l}0.313 \\
(0.27)\end{array}$ & 0.09 & 0.906 & - \\
\hline Verbal Fluency FAS & $\begin{array}{c}47.72 \\
(11.97)\end{array}$ & $\begin{array}{c}44.50 \\
(10.78)\end{array}$ & $\begin{array}{c}38.86 \\
(10.81)\end{array}$ & 5.88 & 0.004 & $\mathrm{VSI}>\mathrm{AI}$ \\
\hline TMT—sequence B & $\begin{array}{l}20.67 \\
(4.72)\end{array}$ & $\begin{array}{l}20.11 \\
(5.18)\end{array}$ & $\begin{array}{l}18.27 \\
(6.13)\end{array}$ & 1.70 & 0.186 & - \\
\hline TMT_connection B & $\begin{array}{l}20.33 \\
(4.25)\end{array}$ & $\begin{array}{l}20.56 \\
(3.36)\end{array}$ & $\begin{array}{l}18.43 \\
(4.70)\end{array}$ & 2.57 & 0.081 & - \\
\hline PPVT total & $\begin{array}{l}117.78 \\
(2.81)\end{array}$ & $\begin{array}{l}117.00 \\
(4.00)\end{array}$ & $\begin{array}{l}113.28 \\
(6.30)\end{array}$ & 6.96 & 0.001 & $\mathrm{VSI}>\mathrm{AI}$ \\
\hline WPwRT total & $\begin{array}{l}12.33 \\
(2.63)\end{array}$ & $\begin{array}{l}12.22 \\
(2.43)\end{array}$ & $\begin{array}{l}11.48 \\
(2.20)\end{array}$ & 1.51 & 0.225 & - \\
\hline Rey-CF_copy_score & $\begin{array}{c}47.22 \\
(13.08)\end{array}$ & $\begin{array}{c}38.33 \\
(15.90)\end{array}$ & $\begin{array}{c}37.26 \\
(13.03)\end{array}$ & 3.95 & 0.022 & $\mathrm{VSI}>\mathrm{AI}$ \\
\hline Rey-CF-copy_time & $\begin{array}{c}51.94 \\
(29.26)\end{array}$ & $\begin{array}{c}56.67 \\
(30.67)\end{array}$ & $\begin{array}{c}54.51 \\
(29.01)\end{array}$ & 0.12 & 0.883 & - \\
\hline Rey-CF_-memory_score & $\begin{array}{c}74.72 \\
(20.61)\end{array}$ & $\begin{array}{l}65.56 \\
(28.17)\end{array}$ & $\begin{array}{l}57.87 \\
(26.44)\end{array}$ & 3.74 & 0.026 & - \\
\hline Rey-CF_memory_time & $\begin{array}{c}45.28 \\
(22.91)\end{array}$ & $\begin{array}{c}43.89 \\
(25.29)\end{array}$ & $\begin{array}{c}47.87 \\
(25.64)\end{array}$ & 0.22 & 0.798 & - \\
\hline
\end{tabular}

Note: VSI—Group with very superior intelligence/SI—Group with superior intelligence/AI—Group with average intelligence.

presented a moderate relationship with all the measures of intelligence. The patterns of these relationships were virtually the same, with a few exceptions such as the relationships between Verbal Comprehension IQ and the Stroop-Comp measures (possibly reflecting the modality of the answer in comprehension, a verbal task) and between Raven's percentiles and correct answers on the Rey-CF. This pattern does not corroborate the hypothesis 
that there is a greater relationship between Gf measures and executive abilities (Arffa, 2007). In fact, other studies have observed a relationship between executive measures and performance on WISC (Ardila et al., 2000) or WAIS (van Aken et al., 2014), measures with a heavy load of Gc (Primi, 2003). Hence, there does not seem to be an important difference in the way performance in the executive and non-executive measures relates to either $\mathrm{G} f$ or $\mathrm{Gc}$ intelligence performance.

In regard to the ANOVA, the result revealed an effect of the level of intelligence on performance in three of the six instruments applied for the assessment of cognitive and executive abilities. The effects were observed in an EF test (FAS) and two tests of non-executive cognitive functions (PPVT and two measures of the Rey-CF). Considering the WISC-III's subtests and factor scores, the same tendency was observed with significant effect on all the measures, except for Assembly Objects. Therefore, these findings enable us to infer that the higher the intelligence measured by the Raven's Progressive Matrices-General Scale, i.e. a Gf measure, the better the performance in most executive and non-executive measures.

Specifically regarding the results from the EF test, the relationship with Gf was already expected (Arffa, 2007; Barbey et al., 2012; Roca et al., 2010). The VSI group presented the best performance in verbal fluency, a complex measure of EF, which involves auditory working memory, switching and inhibition, in addition to oral language abilities (Dias \& Seabra, 2014). There were, however, no differences among the groups in regard to the measures of cognitive flexibility and attention/inhibitory control. This pattern of association between intelligence and EF has been already reported in the literature (Abreu et al., 2014). Friedman and colleagues (2006) for instance, found an association between G $f$ and working memory but no association was found in regard to inhibitory control. Arffa (2007) using a Gc measure did not find an association between intelligence and flexibility. Therefore, the relationship between intelligence and verbal fluency found in this study could be explained by the different demands involved in a complex EF task or, specifically, by the requirement of working memory in this task, what is in agreement with previous findings suggesting a strong relation between working memory and G $f$ in the age range included in our study (Demetriou et al., 2014). The data allow the inference that, even though there is a relationship between EF and Gf, this relationship can be understood in a generic manner and seems to be specific to certain EF abilities (Abreu et al., 2014). Looking at the measures employed in this study, a more consistent relationship took place only between $\mathrm{G} f$ and complex executive ability of verbal fluency, while associations with inhibition and flexibility were weak.

In regard to non-executive functions, a difference among groups was observed in two of three measures. The VSI group presents higher scores than those presented by the SI in regard to vocabulary, which corroborates Lezak and colleagues (2004) and Malloy-Diniz and colleagues (2008) in regard to the relationship between general intelligence and vocabulary; the same is true for visual-spatial processing, which had been already observed in a previous study (Garderen, 2006) that assigned groups according to the WISC-III. Differences among groups were not observed in the performance of the phonological short-term memory task. Such a fact may be related to the $\mathrm{G} f$ task we used, which involves visual-spatial processing.

Concerning the WISC-III measures, the VSI group's performance was superior to the SI group's in regard to Information, which measures acquired knowledge and aspects related to long-term memory. Both groups, VSI and SI, performed better than AI in Similarities, which requires the formation of concepts and inductive reasoning, and in Cubes, which involves visual organization and problem-solving strategies. The SI group performed better than the AI group in Vocabulary, a measure of linguistic performance, and Figures Arrangement, which includes on the requirement to comprehend a sequence of events (temporal sequence) and planning. Finally, the VSI group presented higher scores in comparison to the other two groups in Comprehension, which involves verbal comprehension, knowledge of conventional behavior standards and the ability to think abstractly [see Simões (2002) for an analysis of cognitive demands associated with each WISC-III subtest].

The hypothesis that, if assigned on the basis of a Gf measure, the VSI and SI groups would perform better in EF measures was not confirmed; i.e., no differences were found in the pattern of results between EF tests and non-executive functions tests. In fact, the groups with higher percentiles of intelligence presented improved performances only in regard to complex executive measure in addition to better performances for other cognitive abilities and on the WISC-III subtests, which comprise different aspects, many of which have heavy loads of Gc. Hence, the adolescents grouped by level of intelligence measured by Raven's Test differ both in regard to EF and non-executive functions, in addition to their performance on the WISC-III itself. These results are corroborated by relationships found among the measures, which did not confirm a differential pattern of correlation 
among Gf, Gc and executive and non-executive measures. The results show that the relationships among cognitive, executive and non-executive functions and both Gf and Gc intelligence, are complex and further research should broaden knowledge on the topic. On the other hand, these results are coherent with the assertion that Gf is strongly associated with $g$ (Gustafsson, 1988; Härnqvist et al., 1994). Being an ability that underlies all cognitive abilities, an increase in all the studied abilities, not only in the executive abilities, would in fact be expected given increased $g$.

Further research is suggested in order to overcome this study's limitations, among them the use of a single non-verbal measurement of Gf. A better measurement of Gf could be achieved with a score composed of verbal and non-verbal tasks. Additionally, other instruments should be considered because it is possible that the tests employed here were too easy for this sample of adolescents, such as the Stroop-Comp, in which a tendency to produce a ceiling effect was observed in the measurement of correct answers; also, other variables could be investigated, such as working memory. Another limitation is the use of only one age range, so the findings obtained should not be generalized to other ages or populations. Future research should clarify these findings and even include other approaches. For instance, using the latent variable approach in which a higher control of interrelations among variables is possible could clarify, to some extent, the relationship among intelligence, cognitive and executive functions.

\section{Final Considerations}

The study investigated the relationships among intelligence, EF and non-executive abilities in teenagers, as well as differences in the performances of groups with different levels of intelligence (very superior, superior, and average). A differential pattern of relationships among the measures due to $\mathrm{G} f$ or $\mathrm{G} c$ was not found. In addition to working memory, with greater evidence in the literature, inhibition and flexibility do not seem to be consistently associated with intelligence, and in particular, with Gf. Only the complex ability of verbal fluency was more consistently associated with intelligence. Hence, in addition to the measures used, the relationship between intelligence and EF seems to be due to specific abilities. Additionally, most abilities presented a tendency of progressive performance based on the groups: the higher the Gf, the better the performances in the remaining measures, which does not corroborate the hypothesis that there is greater specific association between G $f$ and EF. The results corroborate improved general performance due to superior intelligence, that is, the $g$ effect.

\section{Acknowledgements}

CNPq (AG Seabra).

\section{References}

Abreu, N., Siquara, G. M., Conceição, A. F. S., Leahy, I., Nikaedo, C., \& Engel, P. (2014). Relações entre Inteligência e Funções Executivas. In A. G. Seabra, J. A. Laros, E. C. de Macedo, \& N. Abreu (Eds.), Inteligência e Funções Executivas (pp. 51-71). São Paulo: Memnon Edições Científicas.

Angelini, A. L., Alves, I. C. B., Custódio, E. M., Duarte, W. F., \& Duarte, J. L. M. (1999). Matrizes Progressivas Coloridas de Raven: Escala Especial. Manual. São Paulo: CETEPP.

Ardila, A., Pineda, D., \& Rosselli, M. (2000). Correlation between Intelligence Test Scores and Executive Function Measures. Archives of Clinical Neuropsychology, 15, 31-36. http://dx.doi.org/10.1093/arclin/15.1.31

Arffa, S. (2007). The Relationship of Intelligence to Executive Function and Non-Executive Function Measures in Sample of Average, above Average and Gifted Youth. Archives of Clinical Neuropsychology, 22, 969-978. http://dx.doi.org/10.1016/j.acn.2007.08.001

Barbey, A. K., Colom, R., Solomon, J., Krueger, F., Forbes, C., \& Grafman, J. (2012). An Integrative Architecture for General Intelligence and Executive Function Revealed by Lesion Mapping. Brain: A journal of Neurology, 135, 1154-1164. http://dx.doi.org/10.1093/brain/aws021

Carroll, J. B. (1993). Human Cognitive Abilities: A Survey of Factor-Analytic Studies. New York: Cambridge University Press. http://dx.doi.org/10.1017/CBO9780511571312

Cattell, R. B. (1987). Intelligence: Its Structure, Growth and Action. New York: North-Holland.

Cattell, R. B. (1998). Where Is Intelligence? Some Answers from the Triadic Theory. In J. Mcardle, \& R. W. Woodcock (Eds.), Human Cognitive Abilities in Theory and Practice (pp. 29-38). New Jersey: Erlbaum. 
Demetriou, A., Spanoudis, G., Shayer, M., van der Ven, S., Brydges, C. R., Kroesbergen, E., Podjarny, G., \& Swanson, H. L. (2014). Relations between Speed, Working Memory, and Intelligence from Preschool to Adulthood: Structural Equation Modeling of 14 Studies. Intelligence, 46, 107-121. http://dx.doi.org/10.1016/j.intell.2014.05.013

Diamond, A. (2013). Executive Functions. Annual Review of Psychology, 64, 135-168. http://dx.doi.org/10.1146/annurev-psych-113011-143750

Dias, N. M., \& Seabra, A. G. (2014). The FAS Fluency Test in Brazilian Children and Teenagers: Executive Demands and the Effects of Age and Gender. Arquivos de Neuro-Psiquiatria (Impresso), 72, 55-62. http://dx.doi.org/10.1590/0004-282X20130213

Dunn, L. M., \& Dunn, D. (1981). Peabody Picture Vocabulary Test-Revised. Circle Pines, MN: American Guidance Service. Figueiredo, V. L. (2002). Wisc III. In J. Cunha (Ed.), Psicodiagnóstico V (pp. 603-614). Porto Alegre: Artmed.

Floyd, R. G., Bergeron, R., Hamilton, G., \& Parra, G. R. (2010). How Do Executive Functions Fit with the Cattell-HornCarroll Model? Some Evidence from a Joint Factor Analysis of the Delis-Kaplan Executive Function System and the Woodcock-Johnson III Tests of Cognitive Abilities. Psychology in the Schools, 47, 721-738.

Friedman, N. P., Miyake, A., Corley, R. P., Young, S. E., Defries, J. C., \& Hewitt, J. K. (2006). Not All Executive Functions Are Related to Intelligence. Psychological Science, 17, 172-179. http://dx.doi.org/10.1111/j.1467-9280.2006.01681.x

Furgueson, C., Greenstein, D., Mcguffin, P., \& Soffer, S. (1999). Efficacy of the WISC-III Short Form for Children Diagnosed with Conduct and Oppositional Defiant Disorders. Archives of Clinical Neuropsychology, 14, 6-7. http://dx.doi.org/10.1093/arclin/14.1.6

Garderen, D. V. (2006). Spatial Visualization, Visual Imagery, and Mathematical Problem Solving of Students with Varying Abilities. Journal of Learning Disabilities, 39, 496-506. http://dx.doi.org/10.1177/00222194060390060201

Gustafsson, J. E. (1988). Hierarchical Models of Individual Differences in Cognitive Abilities. In R. J. Sternberg (Ed.), Advances in the Psychology of Human Intelligence (pp. 35-71). Hillsdale, NJ: Erlbaum.

Härnqvist, K., Gustafsson, J. E., Muthén, B. O., \& Nelson, G. (1994). Hierarchical Models of Ability at Individuals and Class Levels. Intelligence, 18, 165-187. http://dx.doi.org/10.1016/0160-2896(94)90026-4

Horn, J. L. (1991). Measurement of Intellectual Capabilities: A Review of Theory. In K. S. Mcgrew, J. K. Werder, \& R. W. Woodcock (Eds.), Woodcock-Johnson Technical Manual (pp. 197-232). Chicago, IL: Riverside.

Horn, J. L., \& Noll, J. (1997). Human Cognitive Capabilities: Gf-Gc Theory. In D. Flanagan, J. Genshaft, \& P. Harrison (Eds.), Contemporary Intellectual Assessment: Theories, Tests, and Issues (pp. 53-91). New York: Guilford.

Lezak, M. D., Howieson, D. B., \& Loring, D. W. (2004). Neuropsychological Assessment (4th ed.). New York: Oxford University Press.

Malloy-Diniz, L. F., Sedo, M., Fuentes, D., \& Leite, W. B. (2008). Neuropsicología das funções ejecutivas. In D. Fuentes, L. F. Malloy-Diniz, C. H. P. Camargo, \& R. M. Cosenza (Eds.), Neuropsicologia: Teoria e Prática (pp. 187-206). Porto Alegre: Artmed.

Mcgrew, K. S. (1997). Analysis of the Major Intelligence Batteries According to a Proposed Comprehensive Gf-Gc Framework. In D. P. Flanagan, J. L. Genshaft, \& P. L. Harrison (Eds.), Contemporary Intellectual Assessment: Theories, Tests, and Issues (pp. 151-179). New York: Guilford.

Mcgrew, K. S. (2009). CHC Theory and the Human Cognitive Abilities Project: Standing on the Shoulders of the Giants of Psychometric Intelligence Research. Intelligence, 37, 1-10. http://dx.doi.org/10.1016/j.intell.2008.08.004

Mcgrew, K. S., \& Flanagan, D. P. (1998). The Intelligence Test Desk Reference (ITDR): Gf-Gc Cross-Battery Assessment. Boston, MA: Allyn \& Bacon.

Miyake, A., Friedman, N. P., Emerson, M. J., Witzki, A. H., \& Howerter, A. (2000). The Unity and Diversity of Executive Functions and Their Contributions to Complex "Frontal Lobe” Tasks: A Latent Variable Analysis. Cognitive Psychology, 41, 49-100. http://dx.doi.org/10.1006/cogp.1999.0734

Montiel, J., \& Seabra, A. G. (2012). Teste de Trilhas. In A. G. Seabra, \& N. M. Dias (Eds.), Avaliação neuropsicológica cognitiva: Atenção e funções executivas (pp. 69-75). São Paulo: Memnon.

Primi, R. (2003). Inteligência: Avanços nos modelos teóricos e nos instrumentos de Medida. Avaliação Psicológica, 2, 6777.

Rey, A. (1999). Teste de cópia e de reprodução de memória de figuras complexas geométricas complexas: Manual. São Paulo: Casa do Psicólogo.

Riccio, C. A., Hall, J., Morgan, A., \& Hynd, G. W. (1994). Executive Function and the Wisconsin Card Sorting Test: Relationship with Behavioral Ratings and Cognitive Ability. Developmental Neuropsychology, 10, 215-229.

Roca, M., Parr, A., Thompson, R., Woolgar, A., Torralva, T., Antoun, N., Manes, F., \& Duncan, J. (2010). Executive Function and Fluid Intelligence after Frontal Lobe Lesions. Brain: A Journal of Neurology, 133, 234-247. 
http://dx.doi.org/10.1093/brain/awp269

Schelini, P. W. (2006). Teoria das inteligências fluida e cristalizada: Início e evolução. Estudos de Psicologia, 11, $323-332$.

Seabra, A. G. (2012). Teste de Repetição de Palavras e Pseudopalavras. In A. G. Seabra, N. M. Dias, \& F. C. Capovilla (Orgs.), Avaliação Neuropsicológica Cognitiva: Linguagem Oral, Vol. 2, Sao Paulo: Memnon.

Seabra, A. G., Dias, N. M., \& Macedo, E. C. (in press). Teste de Stroop Computadorizado. Sao Paulo: Memnon.

Simões, M. R. (2002). Utilizações da WISC-III na avaliação neuropsicológica de crianças e adolescentes. Paidéia, 12, 113132. http://dx.doi.org/10.1590/S0103-863X2002000200009

Sternberg, R. J. (2008). Psicologia Cognitiva (4th ed.). Porto Alegre: Artmed.

Strauss, E., Sherman, E. M. S., \& Spreen, O. (2006). A Compendium of Neuropsychological Tests: Administration, Norms and Commentary. New York: Oxford University Press.

Sullivan, J. R., Riccio, C. A., \& Castillo, C. R. (2009). Concurrent Validity of the Tower Tasks as Measures of Executive Function in Adults: A Meta-Analysis. Applied Neuropsychology, 16, 62-75. http://dx.doi.org/10.1080/09084280802644243

Van Aken, L., Kessels, R. P. C., Wingbermühle, E. Wiltink, M., van der Heijden, P. T., \& Egger, J. I. M. (2014). Exploring the Incorporation of Executive Functions in Intelligence Testing: Factor Analysis of the WAIS-III and Traditional Tasks of Executive Functioning. International Journal of Applied Psychology, 4, 73-80.

Vance, M. (2004). Avaliação da habilidade de processamento da fala nas crianças: uma análise de tarefas. In M. Snowling, \& J. Stackhouse (Eds.), Dislexia, fala e linguagem (pp. 57-73). Porto Alegre: Artes Médicas.

Zook, N. A., Dávalos, D. B., Delosh, E. L., \& Davis, H. P. (2004). Working Memory, Inhibition, and Fluid Intelligence as Predictors of Performance on Tower of Hanoi and London Tasks. Brain and Cognition, 56, 286-292.

http://dx.doi.org/10.1016/j.bandc.2004.07.003 


\section{Appendix}

Supplementary Table 1. Descriptive statistics for total sample.

\begin{tabular}{|c|c|c|}
\hline & Mean & Std. Deviation \\
\hline Information & 14.81 & 2.548 \\
\hline Similarities & 11.53 & 2.804 \\
\hline Vocabulary & 14.10 & 2.217 \\
\hline Comprehension & 11.16 & 2.004 \\
\hline Complete Figures & 14.04 & 1.997 \\
\hline Figure Arrangement & 13.33 & 2.508 \\
\hline Cubes & 12.88 & 2.240 \\
\hline Assembly Objects & 12.34 & 1.894 \\
\hline Verbal Comprehension IQ & 116.83 & 8.934 \\
\hline Perceptual Organization IQ & 119.77 & 10.264 \\
\hline Stroop-part 3 score & 0.96 & 0.054 \\
\hline Stroop-part 3 RT & 0.78 & 0.283 \\
\hline Stroop interference score & -0.03 & 0.0539 \\
\hline Stroop interference RT & 0.32 & 0.344 \\
\hline Verbal Fluency FAS & 41.03 & 11.428 \\
\hline TMT_-sequence B & 18.91 & 5.854 \\
\hline TMT_connection B & 19.03 & 4.530 \\
\hline PPVT total & 114.44 & 5.974 \\
\hline WPwRT total & 11.73 & 2.297 \\
\hline Rey-CF_copy_score & 39.04 & 13.770 \\
\hline Rey-CF-copy_time & 54.79 & 29.020 \\
\hline Rey-CF_-memory_score & 60.88 & 26.857 \\
\hline Rey-CF-memory_time & 46.86 & 25.037 \\
\hline Raven Percentile & 57.98 & 23.372 \\
\hline
\end{tabular}


Supplementary Table 2. Full Matrix of correlations.

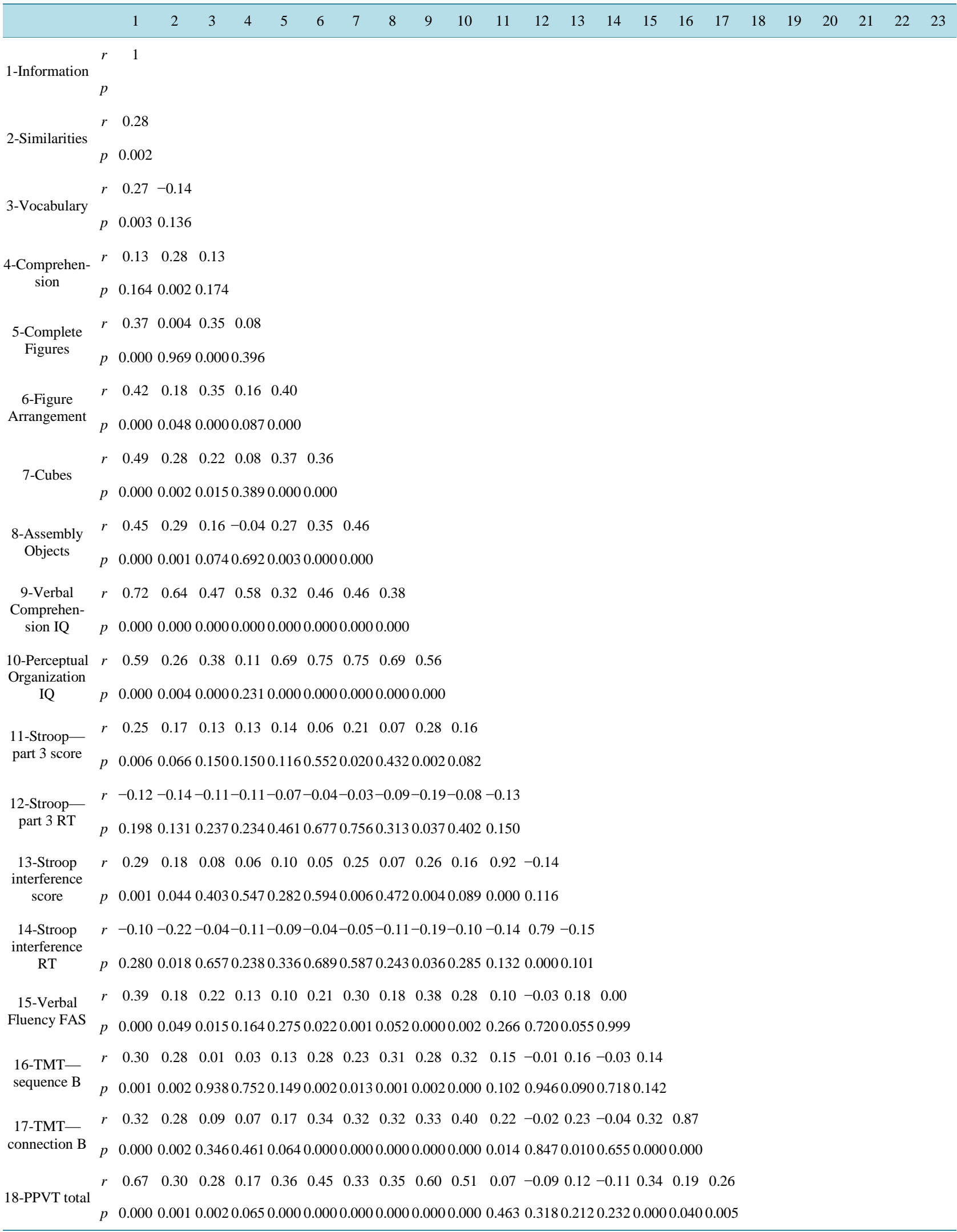


S. Godoy et al.

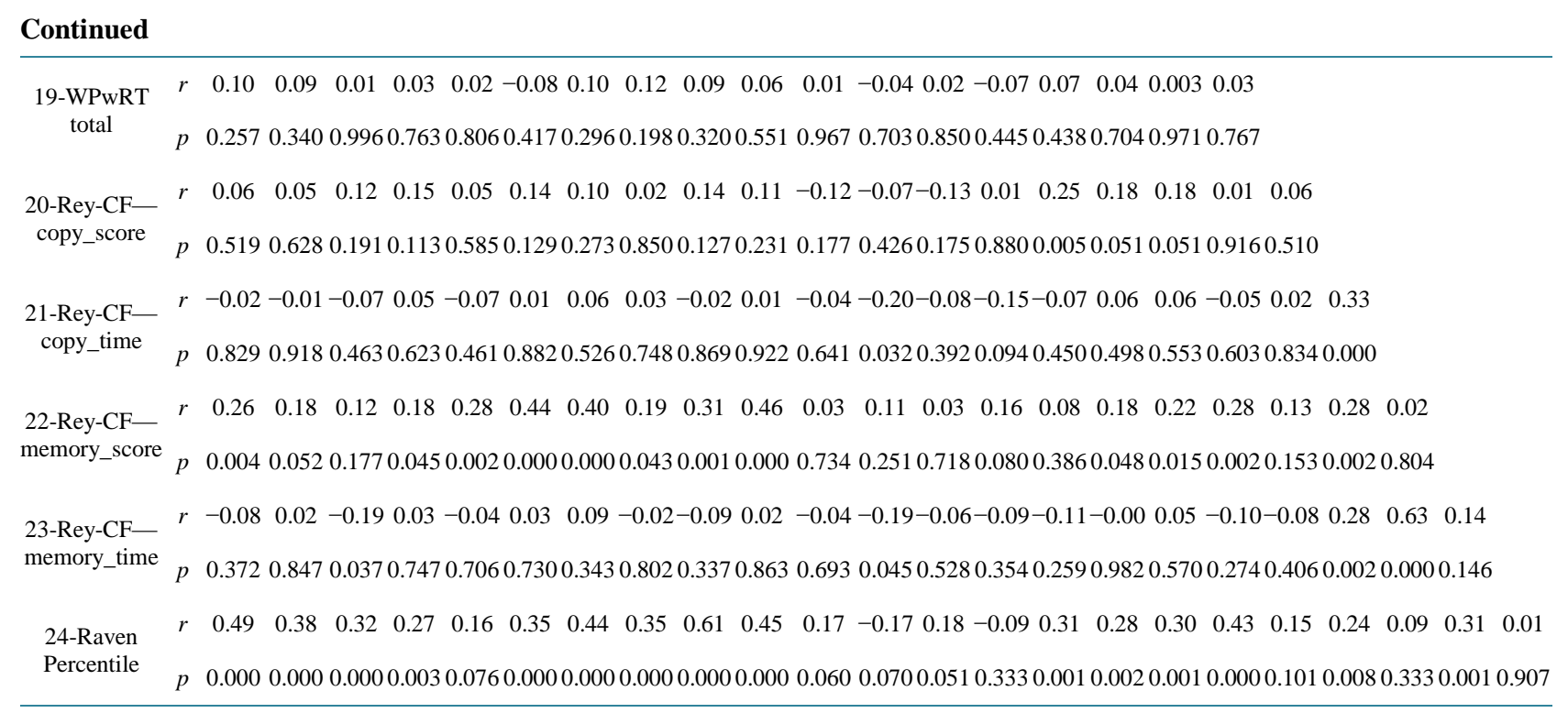


Scientific Research Publishing (SCIRP) is one of the largest Open Access journal publishers. It is currently publishing more than 200 open access, online, peer-reviewed journals covering a wide range of academic disciplines. SCIRP serves the worldwide academic communities and contributes to the progress and application of science with its publication.

Other selected journals from SCIRP are listed as below. Submit your manuscript to us via either submit@scirp.org or Online Submission Portal.
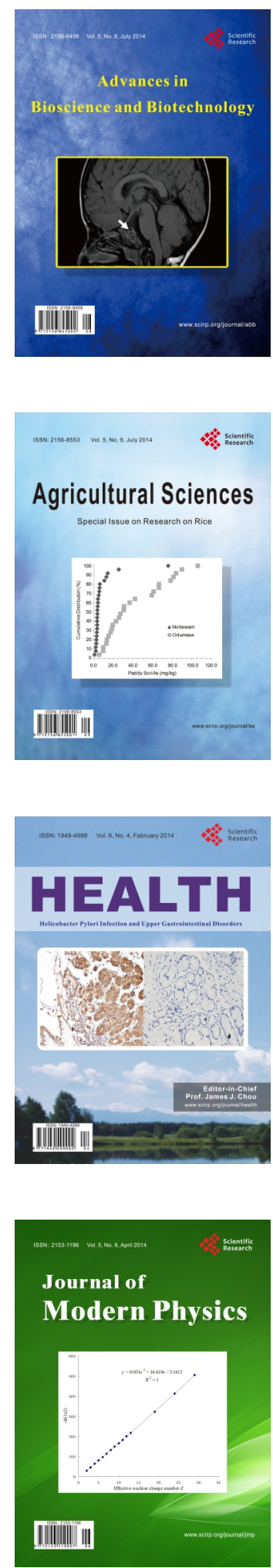
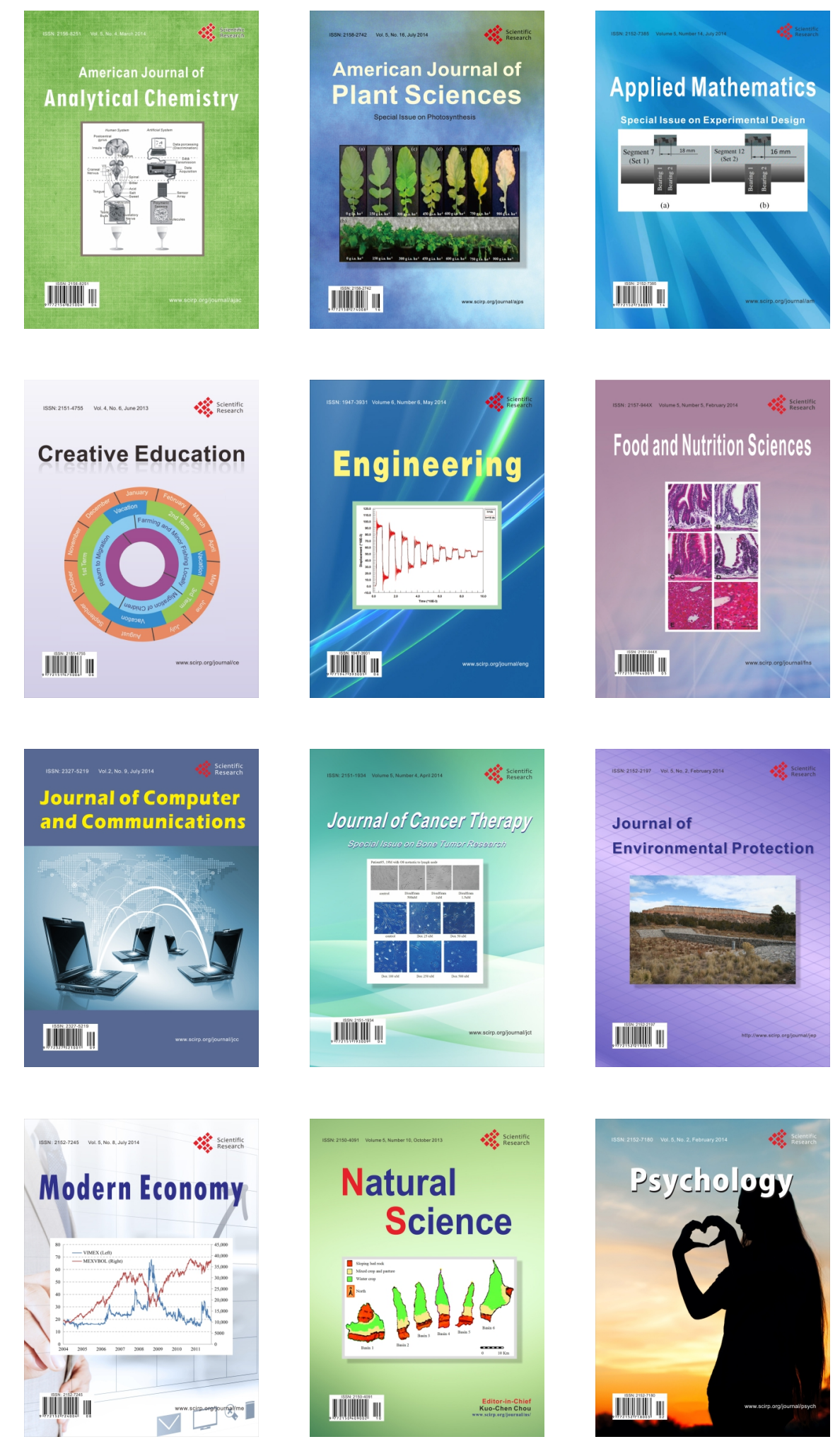